\title{
TINGKAT PENGETAHUAN IBU MENETEKI MEMPENGARUHI PEMILIHAN JENIS KONTRASEPSI SUNTIK DI PUSTU KANGENAN PAMEKASAN
}

\author{
Nurul Kamariyah \\ ( UNUSA, FKK, JL. SMEA NO. 57 SURABAYA ) \\ Email : nurulkamariyah@unusa.ac.id
}

\begin{abstract}
Contraceptive injection acceptors in Pamekasan District have reached 66.85\%. The appropriate type of contraceptive injection for the breastfeeding mothers is the three-month injection because it doesn't disturb the lactation process. In Pustu (supporting community health center) Kangenan, almost all breastfeeding mothers choose one-month contraceptive injection. The influencing factor for them to choose the contraceptive injection is knowledge. Therefore, this research was purposed to find out the relationship between the breastfeeding mothers' knowledge and their choice for contraceptive injection. The design of this research was analytic-observational done by applying the cross sectional approach. The population involved 48 breastfeeding mothers choosing the contraceptive injection. The samples included the simple random sampling involved 42 respondent The research done in July 2014 used the instrument of questionnaire and LPD (data collection sheet). The result of the research showed that among 23 respondents with low level of knowledge, almost all of them (78.3\%) chose one-month contraceptive injection (cyclofem) which didn't meet their needs. Moreover, the result of data analysis using SPSS program for Windows and Mann-Whitney test revealed that $\rho=0.003<\alpha 0.05$ which proved that there was a relationship between the breastfeeding mothers' knowledge and their choice for contraceptive injection. The conclusion of this research was that the breastfeeding mothers' knowledge and their choice for contraceptive injection were related. Hence, the breastfeeding mothers should choose the three-month contraceptive injection because it gives no influence to the breast milk. Besides, the maximum counseling should also be done to the forthcoming acceptors to choose the appropriate contraceptive method.
\end{abstract}

\begin{abstract}
ABSTRAK
Akseptor KB suntik di kabupaten Pamekasan mencapai 66,85\%. KB suntik yang sesuai untuk ibu meneteki adalah KB suntik 3 bulan karena tidak mengganggu ASI, di Pustu Kangenan ibu meneteki hampir seluruhnya memakai KB suntik 1 bulan. Faktor yang mempengaruhi ibu meneteki memilih kontrasepsi suntik salah satunya adalah pengetahuan. Penelitian ini bertujuan untuk mengetahui hubungan pengetahuan ibu meneteki dengan pemilihan kontrasepsi suntik di Pustu Kangenan Pamekasan. Desain penelitian analitik observasional bersifat cross sectional. Populasi ibu meneteki yang menggunakan KB suntik sebesar 48 orang, sampel adalah sebagian n dari populasi (simple randim sampling) sebesar 42 responden. Penelitian dilakukan bulan Juli 2014, menggunakan instrumen kuesioner dan LPD (Lembar Pengumpulan Data) Hasil penelitian menunjukkan bahwa dari 23 responden yang berpengetahuan kurang hampir seluruhnya $(78,3 \%)$ menggunakan kontrasepsi suntik 1 bulan (cyclofem), hal ini tidak sesuai dengan kebutuhannya. Analisis data menggunakan SPSS for windows dengan uji mann whitney didapatkan hasil $\rho=$ $0,003<\alpha=0,05$ yang berarti ada hubungan antara tingkat pengetahuan ibu meneteki dengan pemilihan jenis kontrasepsi suntik.Simpulan dalam penelitian ini terdapat hubungan antara
\end{abstract}


tingkat pengetahuan ibu meneteki dengan pemilihan jenis kontrasepsi suntik. Saran bagi ibu meneteki sebaiknya memilih KB suntik 3 bulan karena tidak mempengaruhi ASI sehingga perlu dilakukan konseling secara maksimal kepada para calon akseptor sebelum memilih kontrasepsi yang cocok.

Kata kunci : Pengetahuan ibu meneteki, Pemilihan kontrasepsi suntik.

\section{PENDAHULUAN}

Kontrasepsi (KB) adalah bagian dari pelayanan kesehatan reproduksi untuk mengatur kehamilan dan merupakan hak setiap individu sebagai mahkluk seksual (Saifudin,AB, 2006 :U-46). Kontrasepsi suntik merupakan salah satu metode kontrasepsi yang tujuannya mengatur kesuburan atau menjarangkan kehamilan dengan syarat-syarat efektifitasnya cukup tinggi, kegagalan kurang dari $1 \%$, dapat punya anak lagi, dapat dipakai sesuai dengan jarak kehamilan yang direncanakan dan tidak kalah pentingnya tidak menghambat produksi ASI (Depkes, 2010).

Kontrasepsi suntik sudah lama menjadi kontrasepsi yang menjanjikan walaupun baru mencapai potensi penuh dalam 15 tahun terakhir. Di seluruh dunia kontrasepsi suntik terhitung hanya $1-2 \%$ dari keseluruhan penggunaan kontrasepsi, walaupun di beberapa Negara tertentu salh satunya di Indonesia metode ini lebih luas digunakan (Glasier A, 2006). KB suntik sendiri terdiri dari 2 jenis yaitu KB suntik 3 bulan (mengandung hormone progestin) dan KB suntik 1 bulan (mengandung campuran hormone estrogen dan progesterone). Salah satu sasaran dari kontrasepsi adalah pasangan usia subur yang didalamnya termasuk ibu meneteki. Karena itu sebaiknya ibu meneteki manghindari KB hormonal berbasis hormonal estrogen, karena dapat mengurangi jumlah produksi ASI (www.wikipedia.com).

Berbagai faktor yang mempengaruhi seseorang menggunakan alat kontrasepsi yaitu status sosial (pengetahuan, pendidikan, pekerjaan), demografis (umur dan jumlah anak), pengalaman menggunakan $\mathrm{KB}$, aktivitas kemasyarakatan, peran dalam pengambilan keputusan rumah tangga, tempat tinggal, kesehatan, dan metode kontrasepsi (Widyaningrum A, 1999). Dari berbagai faktor tersebut diatas salah satunya adalah pengetahuan. Pengetahuan tentang pengendalian kelahiran dan Keluarga Berencana merupakan salah satu aspek penting kearah pemahaman tentang berbagai alat atau cara ber KB yang tepat dan efektif (Surbekti, 2008).

Data yang didapat di kabupaten Pamekasan jumlah pasangan usia subur sebesar 154.523 dan terdapat 118.447 (77,80\%) akseptor KB dengan jumlah akseptor KB suntik mencapai 101.780 (66.85\%). Menurut studi pendahuluan yang diambil di Puskesmas Pembantu Kelurahan Kangenan Kabupaten Pamekasan pada Februari 2008 sampai Januari 2009 jumlah PUS 966 dan terdapat jumlah akseptor KB aktif 722 akseptor (74,74\%). Bila dirici lebih lanjut jumlah peserta KB terbanyak adalah suntik. Adapun rinciannya yaitu suntik 480 (66,48\%), IUD 9 (1,24\%), Implant 40 $(5,54 \%)$, pil $172(23,82 \%)$, MOP $1(0,14 \%)$, 
MOW 18 (2,50\%), khusus ibu meneteki yang menggunakan $\mathrm{KB}$ suntik yang berkunjung sebanyak 42 orang, dan yang menggunakan KB suntik progestin ( 3 bulan) sebanyak 7 orang $(16,66 \%)$ sedangkan sisanya 35 orang $(83,33 \%)$ menggunakan KB cyclofem (1 bulan). Hal ini menunjukkan bahwa masih banyak ibu meneteki yang masih belum tepat dalam penggunaan atau pemilihan kontrasepsi suntik. Hal ini merupakan masalah yang seharusnya diantisipasi karena sebaiknya seperti yang dijelaskan teori di awal seharusnya ibu meneteki menghindari KB yang mengandung estrogen ( $\mathrm{KB}$ suntik 1 bulan).

Setelah diambil data dari 10 akseptor, terdapat 7 (70\%) akseptor memakai KB suntik 1 bulan dengan alasan sudah pernah menggunakan KB suntik 1 bulan dan cocok dengan $\mathrm{KB}$ suntik 1 bulan sedangkan 3 (30\%) akseptor yang menggunakan KB suntik 3 bulan dengan alasan tidak tiap bulan harus kembali untuk suntik KB. Dari 7 akseptor yang menggunakan $\mathrm{KB}$ suntik 1 bulan, hanya 1 orang $(14,28 \%)$ yang mengetahui tentang pengaruh $\mathrm{KB}$ suntik 1 bulan terhadap produksi ASI sedangkan 6 orang $(85,71 \%)$ tidak tahu pengaruh penggunaan $\mathrm{KB}$ suntik 1 bulan terhadap ASI, dan dari 7 akseptor yang menggunakan KB suntik 1 bulan tersebut 5 orang mengatakan air susunya berkurang, dan 2 lainnya mengatakan berhenti menyusui bayinya karena produksi air susunya sedikit. Dari ketidaktahuan masyarakat khususnya ibu meneteki dalam menggunakan alat kontrasepsi yang aman berakibat mengurangi produksi ASI, mempengaruhi tumbuh kembang bayi dan meningkatkan resiko pembekuan darah (Saifudin, AB, 2003 : U-46).

Bagi para pelaksana program KB hendaknya betul-betul memberikan konseling secara lengkap kepada calon peserta KB, sehingga akseptor khususnya BUTEKI mengerti tentang KB yang diikuti yang tidak mengganggu atau merugikan kesehatannya.Berdasarkan alasan tersebut diatas dalam peneliti tertarik untuk meneliti tentang tingkat pengetahuan ibu meneteki dengan penggunaan kontrasepsi suntik.

\section{METODE}

Desain yang digunakan dalam penelitian adalah analitik observasional yang bersifat cross sectional. Populasi dalam penelitian ini adalah seluruh ibu meneteki yang menggunakan kontrasepsi suntik yang ada di Pustu Kangenan Pamekasan sebesar 48 orang. sampel yang digunakan dalam penelitian ini adalah sebagian ibu meneteki yang menggunakan KB suntik yang bersedia menjadi responden dan dapat berkomunikasi dengan baik (dapat baca dan tulis). Besar sampel dalam penelitian ini adalah total populasi sebesar 42 orang. Cara pengambilan sampel dalam penelitian ini adalah dengan tehnik simple random sampling.

\section{HASIL}

Tabel 5.1 : Distribusi frekuensi umur ibu meneteki yang menggunakan KB suntik di Pustu Kelurahan Kangenan Kecamatan Pamekasan pada bulan Juli 2014 


\begin{tabular}{lll}
\hline Umur & Frekuensi & Persentase \\
\hline$<20$ tahun & 4 & 9,5 \\
$20-35$ tahun & 33 & 78,6 \\
$>35$ tahun & 5 & 11,9 \\
\hline Jumlah & 42 & 100 \\
\hline
\end{tabular}

Sumber : Data primer 2014

Berdasarkan tabel 5.1 menunjukkan bahwa hampir seluruhnya $(78,6 \%)$ dari 42 responden berumur 20-30 tahun.

Tabel 5.2 :Distribusi frekuensi pendidikan ibu meneteki yang menggunakan KB suntik di Pustu Kelurahan Kangenan Kecamatan Pamekasan pada bulan Juli 2014

\begin{tabular}{lll}
\hline Pendidikan & Frekuensi & Persentase \\
\hline $\begin{array}{l}\text { Dasar } \\
\text { pendidikan }\end{array}$ & 25 & 59,5 \\
Menengah & 13 & 313 \\
Tinggi & 4 & 9,5 \\
\hline Jumlah & 42 & 100
\end{tabular}

Sumber : Data primer 2014

Berdasarkan tabel 5.2 menunjukkan bahwa sebagian besar $(59,5 \%)$ dari 42 responden adalah berpendidikan dasar.

Tabel 5.3: Distribusi frekuensi pekerjaan ibu meneteki yang menggunakan KB suntik di Pustu Kelurahan Kangenan Kecamatan Pamekasan pada bulan Juli 2014

\begin{tabular}{lll}
\hline Pekerjaan & Frekuensi & Persentase \\
\hline Tidak bekerja & 34 & 81 \\
Bekerja & 8 & 19 \\
\hline Jumlah & 42 & 100 \\
\hline \multicolumn{2}{c}{ Sumber : Data primer 2014 }
\end{tabular}

Berdasarkan tabel 5.3 menunjukkan bahwa hampir seluruhnya (81\%) dari 42 responden adalah tidak bekerja.

Tabel 5.4 : Distribusi frekuensi paritas ibu meneteki yang menggunakan KB suntik di Pustu Kelurahan Kangenan Kecamatan Pamekasan pada bulan Juli 2014 .

\begin{tabular}{lll}
\hline Paritas & Frekuensi & Persentase \\
\hline Primipara & 26 & 61,9 \\
Multipara & 15 & 38,1 \\
\hline Jumlah & 42 & 100 \\
\hline
\end{tabular}

Sumber : Data primer 2014

Berdasarkan tabel 5.4 menunjukkan bahwa hampir seluruhnya $(61,9 \%)$ dari 42 responden adalah tidak bekerja.

Tabel 5.5 : Distribusi frekuensi pengetahuan ibu meneteki yang menggunakan KB suntik di Pustu Kelurahan Kangenan Kecamatan Pamekasan pada bulan Juli 2014

\begin{tabular}{lll}
\hline Pengetahuan & Frekuensi Persentase
\end{tabular}




\begin{tabular}{lcc}
\hline Baik & 11 & 26,2 \\
Cukup & 8 & 19,0 \\
Kurang & 23 & 54,8 \\
\hline \multicolumn{1}{c}{ Jumlah } & 42 & 100 \\
\hline
\end{tabular}

Sumber : Data primer 2014

Berdasarkan tabel 5.5 menunjukkan bahwa sebagian besar $(54,8 \%)$ dari 42 reponden adalah berpengetahuan kurang.

Tabel 5.6 : Distribusi frekuensi penggunaan kontrasepsi suntik ibu meneteki di Pustu Kelurahan Kangenan Kecamatan Pamekasan pada bulan Juli 2014 .

\begin{tabular}{lll}
\hline Jenis KB & Frekuensi & Persentase \\
\hline 1 & 24 & 57,1 \\
bulan(cyclofem) & & \\
$3 \quad$ bulan & 18 & 42,9 \\
(DMPA) & & \\
\hline Jumlah & 42 & 100 \\
\hline
\end{tabular}

Sumber : Data primer 2014

Berdasarkan tabel 5.6 menunjukkan bahwa sebagian besar $(57,1 \%)$ dari 42 responden adalah menggunakan $\mathrm{KB}$ suntik 1 bulan (cyclofem).

a. Hubungan tingkat pengetahuan ibu meneteki dengan pemilihan jenis kontraepsi suntik Tabel 5.7 : Tabel silang hubungan pengetahuan ibu meneteki dengan pemilihan kontrasepsi suntik di Pustu Kelurahan Kangenan Kecamatan

\begin{tabular}{|c|c|c|c|c|c|c|}
\hline \multirow{3}{*}{ Pengetahuan } & \multicolumn{4}{|c|}{$\begin{array}{l}\text { Penggunaan } \\
\text { kontrasepsi }\end{array}$} & \multirow{2}{*}{\multicolumn{2}{|c|}{ Jumlah }} \\
\hline & \multicolumn{4}{|c|}{$\begin{array}{l}\text { 1 bin } \quad \text { (cyclofem) } \\
3 \text { bln (DMPA) }\end{array}$} & & \\
\hline & $\mathrm{N}$ & $\%$ & $\mathrm{n}$ & $\%$ & $\mathrm{n}$ & $\%$ \\
\hline Baik & 3 & 27,3 & 8 & 72,7 & 11 & 100 \\
\hline Cukup & 3 & 37,5 & 5 & 62,5 & 8 & 100 \\
\hline Kurang & 18 & 78,3 & 5 & 21,7 & 23 & 100 \\
\hline Jumlah & 24 & & 18 & & 42 & 100 \\
\hline
\end{tabular}

Sumber : Data primer 2014

Berdasarkan tabel 5.7 menunjukkan bahwa dari 23 responden yang berpengetahuan kurang hampir seluruhnya $(78,3 \%)$ memilih kontrasepsi suntik 1 bulan (cyclofem).

Berdasarkan analisa data dengan menggunakan uji Mann Whitney di dapatkan hasil $\rho=0,003<$ $\alpha=0,05$ berarti $\mathrm{H}_{0}$ ditolak yaitu ada hubungan tingkat pengetahuan ibu meneteki dengan pemilihan kontrasepsi suntik.

\section{PEMBAHASAN}

Pengetahuan ibu meneteki tentang kontrasepsi suntik

Berdasarkan tabel 5.5 menunjukkan bahwa sebagian besar responden $54,8 \%$ memiliki pengetahuan kurang tentang kontrasepsi suntik. Faktor yang mempengaruhi pengetahuan antara lain umur, pendidikan, sosial ekonomi.

Berdasarkan tabel 5.1 hampir seluruhnya $(78,6 \%)$ responden berumur 20-35 tahun, hal ini menunjukkan ibu meneteki baru menginjak usia dewasa dan belum matang, sehingga cenderung memiliki pengetahuan yang kurang. Karena pengetahuan didapat sedikit 
demi sedikit mulai dari usia muda sehingga semakin bertambahnya usia pengetahuan dan pengalaman yang dimiliki semakin banyak dan baik. Parita juga mempengaruhi pengetahuan ibu meneteki karena sebagian besar responden adalah primipara, maka pengalaman yang mereka dapat juga kurang mereka lebih mengikuti kepercayaan yang dianut orang yang mereka anggap lebih tua.

Selain faktor umur, faktor pendidikan juga berpengaruh terhadap tingkat pengetahuan khususnya ibu meneteki. Karakteristik tingkat pendidikan responden sebagian besar $(59,5 \%)$ berpendidikan dasar hal ini menunjukkan dalam memperoleh informasi juga kurang dan cenderung lebih lamban dalam untuk beradaptasi terhadap perubahan perilaku yang baru dikenal.

Selain dua faktor tersebut faktor sosial ekonomi juga mempengaruhi tingkat pengetahuan seseorang. Berdasarkan hasil penelitian hampir seluruhnya $(81 \%)$ responden tidak bekerja, hal ini bisa dikatakan bahwa responden cenderung meluangkan waktu dirumah untuk mengurusi rumah tangga, diri sendiri dan keluarga. Sehingga mereka cenderung kurang memperhatikan hal yang mereka anggap kurang penting namun sebenarnya sangat berpengaruh terhadap kesehatannya seperti halnya pada kontrasepsi.

Hasil penelitian diatas sesuai dengan teori Latipun (2011) bahwa tingkat pengetahuan di pengaruhi oleh faktor umur dan pendidikan,intelegensi serta sosial ekonomi. Semakin tua umur seseorang, semakin kontruktif dalam menggunakan kopling terhadap masalah yang di hadapi,makin muda seseorang akan mempengaruhi terhadap pengambilan keputusan, tingkat pendidikan seseorang mempengaruhi pandangannya dan prilakunya, karena itu akan berbeda sikap dan perilaku seseorang yang berpendidikan tinggi di banding yang berpendidikan rendah. Hal ini juga diperkuat dengan teori yang dikemukakan oleh Notoatmodjo,S ( 2003 ) yaitu pengetahuan merupakan domain yang penting dalam membentuk tindakan seseorang. Bertambah banyak pengetahuan yang di peroleh seseorang akan bertambah terbuka pintu hati mereka untuk menerima gagasan dan informasi baru ( subekti,S.2003).

Pemilihan Jenis Kontrasepsi suntik

Berdasarkan tabel 5.6 menunjukkan bahwa $57,1 \%$ memilih KB suntik 1 Bulan ( Cyclofem ), hal ini tidak sesuai dengan kebutuhan ibu meneteki karena seharusnya ibu meneteki memilih KB suntik 3 bulan karena tidak mempengaruhi ASI. Faktor yang mempengaruhi pemilihan jenis kontrasepsi antara lain umur, paritas, status ekonomi, pekerjaan dan pendidikan.

Di Indonesia kontrasepsi suntik sangat populer selain karena mudah ibu-ibu akseptor "jatuh cinta" lantaran segi praktisanya yaitu terbebas dari faktor lupa,berdaya kerja lama ,tidak perlu memakainya setiap kali akan senggama. Menurut Wydianingrum ,A.(2009) faktor-faktor yang mempengaruhi seseorang menggunakan alat kontrasepsi yaitu status sosial, pendidikan , pengetahuan dan pekerjaan, demografis ( umur dan jumlah anak ), pengalaman ber $\mathrm{KB}$, aktifitas kemasyarakatan, peran dalam mengambil keputusan.

Berdasarkan hasil penelitian pada tabel 5.1 umur responden hampir seluruhnya berusia 20-30 tahun, dimana cenderung memilih KB suntik 1 bulan karena ingin mendapat menstruasi secara teratur dan tidak gemuk tanpa melihat efek samping dari KB suntik 1 bulan yang dapat mempengaruhi produksi ASI.

Begitu pula dengan paritas atau jumlah anak, sebagian responden $(61,9 \%)$ adalah primipara memilih $\mathrm{KB}$ suntik 1 bulan dengan alasan kesuburannya akan cepat kembali setelah 
berhenti menjadi akseptor dengan demikian lebih cepat pula memiliki anak, pengalaman juga menjadi alasan responden memilih KB suntik 1 bulan mengingat ini adalah anak pertama. Hal ini juga dipengaruhi oleh faktor sosial budaya dimana KB suntik dianggap hanya menunda kehamilan bukan menghentikan kehamilan seperti alat kontrasepsi lainnya.

Selain faktor umur dan paritas, status ekonomi dan pekerjaan juga berpengaruh dalam pemilihan kontrasepsi. Berdasarkan tabel 5.3 hampir seluruh responden tidak bekerja, sehingga responden cenderung memilih $\mathrm{KB}$ suntik karena lebih murah dibandingkan dengan alat kontrasepsi yang lain. Dari beberapa faktor yang telah dikemukakan, faktor pengetahuan juga tidak kalah pentingnya dalam pemilihan jenis kontrasepsi. Dengan pendidikan responden yang sebagian besar adalah berpendidikan dasar menunjukkan bahwa pengetahuan yang dimiliki juga kurang sehingga berpengaruh juga terhadap pemilihan alat kontrasepsi yang sesuai dengan kebutuhan ibu meneteki.

Menurut Subekti,S ( 2008 ) dari berbagai faktor tersebut pengetahuan tentang pengendalian kelahiran dan keluarga berencana merupakan salah satu aspek penting ke arah pemahaman tentang berbagai cara kontrasepsi dan selanjutnya.

Hubungan pengetahuan ibu meneteki dengan pemilihan kontrasepsi suntik.

Berdasarkan tabel 5.7 menunjukkan bahwa dari 23 reponden yang berpengetahuan kurang hampir seluruhnya $(78,3 \%)$ memilih $\mathrm{KB}$ suntik 1 bulan.

Signifikan hasil hitung sebesar 0,003 $<0,05 \mathrm{H}_{1}$ di terima berarti ada hubungan pengetahuan ibu meneteki dengan pemilihan jenis kontrasepsi suntik. Semakin tinggi pengetahuan ibu meneteki, semakin tepat dalam memilih $\mathrm{KB}$ yang sesuai dengan kebutuhannya yaitu $\mathrm{KB}$ suntik 1 bulan. Hasil penelitian di atas sesuai dengan teori Notoatmodjo,S ( 2008 ), bahwa pengetahuan merupakan domain yang sangat penting dalam membentuk tindakan seseorang.

Menurut Widyaningrum,A (2009) Bahwa pengalaman menggunakan salah satu metode kontrasepsi yang menunjang pemahaman akseptor tentang metode kontrasepsi. Semakin lama akseptor tahu tentang metode kontrasepsi, semakin lama akseptor menggunakan KB suntik diasumsikan pengetahuan mereka serta keberlangsungan pengguna $\mathrm{KB}$ suntik semakin baik. Begitu pula pengetahuan individu tentang $\mathrm{KB}$ penting untuk membentuk seseorang menjadi akseptor KB.

Makin banyak Informasi (lengkap dan jujur ) mengenai semua jenis alat kontrasepsi baik keuntungan, kerugian, dan efek sampaing maka ibu meneteki dapat menentukan alat kontrasepsi apa yang cocok untuk dirinya. Sebaiknya bagi para pelaksana Program KB betul betul memberikan Konseling dan penyuluhan di sertai dengan kualitas dan kemudahan layanan kepada calon peserta KB, sehingga akseptor khusunya Ibu meneteki mengerti tentang KB yang cocok untuk dirinya, yaitu ibu meneteki memilih kontrasepsi yang tidak mengandung progestin dan menghindari kontrasepsi yang mengandung estrogen karena berpengaruh terhadap produksi ASI.

\section{SIMPULAN}

Dari hasil penelitian dan pembahasan diatas maka dapat diambil kesimpulan bahwa di Pustu Kangenan Pamekasan adalah sebagai berikut :

1. Ibu meneteki sebagian besar memiliki pengetahuan yang kurang .

2. Ibu meneteki sebagian besar memilih kontrasepsi suntik 1 bulan (cyclofem), 
3. Terdapat hubungan pengetahuan ibu meneteki dengan pemilihan jenis kontrasepsi suntik.

\section{DAFTAR PUSTAKA}

Arikunto,S. 2008. Prosedur Penelitian Suatu Pendekatan Praktek. PT.Rineka Cipta : Jakarta.

BKKBN. 2007. Laporan BKKBN Kabupaten Pamekasan, Hasil Pelayanan Peserta Aktif Pemerintah dan Swasta Bulan Februari 2008 Januari 2009.

Glasier, A. 2006, Keluarga Berencana dan Kesehatan Reproduksi, EGC : Jakarta

Hartanto, H. 2002. Keluarga Berencana dan Kontrasepsi. Pustaka Sinar Harapan : Jakarta.

Juliantoro, D. 2000. 30 Tahun Cukup Keluarga Berencana dan Hak Konsumen. Pustaka Sinar Harapan : Jakarta.

Notoatmodjo, Soekijo. 2008. Metodologi Penelitian Kesehatan. Rineka Cipta : Jakarta.

Notoatmodjo, Soekijo. 2006. Pendidikan dan Perilaku Kesehatan Masyarakat. Jakarta.

Notoatmodjo, Soekijo. 2007. Promosi Kesehatan dan Ilmu Perilaku. Rineka Cipta : Jakarta.

Nursalam, 2003. Konsep dan Penerapan Metodologi Penelitian Ilmu Keperawatan. Salemba Medika : Jakarta.

Prihartono, Y. 2009. Kapita Selekta Peningkatan Pelayanan Kontrasepsi. BKKBN : Jakarta.
Prawiroharjo, S. 1999. Ilmu Kandungan, Yayasan Bina Pustaka Sarwono Prawirohardjo : Jakarta.

Saifudin, AB. 2003. Buku Panduan Praktis Pelayanan Kontrasepsi. Yayasan Bina Pustaka Sarwono Prawirohardjo : Jakarta.

Saifudin, AB. 2006. Buku Panduan Praktis Pelayanan Kontrasepsi. Yayasan Bina Pustaka Sarwono Prawirohardjo : Jakarta.

Surbekti, S. 2008. Survei Demografi dan Kesehatan Indonesia 2002-2003, BKKBN : Jakarta.

Suradi, Ruslina. 2004. Manajemen Laktasi Edisi 2. Program Manajemen Laktasi Perkumpulan Perinatologi Indonesia : Jakarta.

Siswosudarno, HR. 2001. Tehnologi Kontrasepsi. Gadjah Mada University Press : Jogjakarta.

Sperof, L. 2005. Pedoman Klinis Kontrasepsi, edisi 2. EGC : Jakarta

Wijono, W. 2010. Pedoman Penanggulangan Efek Samping / Kompilkasi Kontrtasepsi. Depkes RI : Jakarta.

Wiknjosastro, H. 2005. Ilmu Kebidanan. Yayaysan Bina Pustaka Sarwono Prawirohardjo : Jakarta.

Widyaningrum, A. 2009. Kualitas Pelayanan Keluarga Berencana Dalam Perspektif Klien. Pusat Penelitian Kependudukan UGM dengan Ford Foundation : Jogjakarta. 
